\title{
Ensino de Programação nas Escolas: Um relato de experiência
}

\author{
Gabriel H. Montoanelli, Joana P. Rolim, Fabiana F. F. Peres, Claudio R. M. Mauricio, Eliane N. Pereira, Rômulo C. Silva \\ Ciência da Computação. Centro de Engenharias e Ciências Exatas. \\ Universidade Estadual do Oeste do Paraná. Unioeste \\ Foz do Iguaçu. Paraná. Brasil. \\ fabiana.peres@unioeste.br
}

\begin{abstract}
Embora a capacidade de realizar encadeamento sequencial coerente de instruções para resoluções de problemas seja considerada uma capacidade humana natural, a falta do ensino desse conteúdo no ensino fundamental e médio, é apontado como um dos principais fatores para a evasão dos cursos que envolvem programação diretamente, como ciência da computação e engenharia da computação. Uma maneira de trabalhar para alteração desse quadro é através da aplicação de cursos de extensão, focados em lógica computacional, a exemplo da experiência relatada neste artigo, em que foram realizadas atividades de resoluções de situação-problemas para alunos do $7^{\circ}$ ao $9^{\circ}$ ano no contra-turno de uma escola estadual no Estado do Paraná.
\end{abstract}

Keywords-pensamento computacional; ensino fundamental; programação;

\section{INTRODUÇÃO}

Nos últimos anos, vem surgindo um grande incentivo por parte das instituições de ensino e da Sociedade Brasileira de Computação (SBC) para disseminar o pensamento computacional e conceitos básicos de computação no ensino fundamental e médio levando em consideração que seus benefícios se tornaram essenciais a todos os estudantes e profissionais, e não somente para aqueles da área de computação [1]. Essa estratégia é uma tentativa de levar computação no ensino básico, pois muitos tem o primeiro contato somente no ensino superior, levando a uma grande dificuldade inicial, pois exige uma nova forma de pensar [2].

Pode-se afirmar que a capacidade de desenvolvimento de algoritmos complexos é fortemente relacionada à lógica do programador. Sendo assim, é uma das primeiras habilidades a serem trabalhadas quando se estuda programação. Por conta disso, se torna um dos principais fatores para a evasão dos cursos que envolvem programação diretamente, como ciência da computação e engenharia da computação.

Atualmente a tecnologia está evoluindo em uma velocidade exponencial; entretanto as academias não conseguem capacitar pessoas na mesma velocidade devido ao baixo índice de formandos, gerando um déficit de profissionais. Mesmo havendo grande oportunidades profissionais muitos jovens acabam não se interessando pela área, talvez pela desinformação sobre o que se trata o curso.

Considerando o contexto atual, esse artigo relata uma experiência de aplicação de um curso de extensão de lógica computacional, com atividades de resoluções de situaçãoproblemas, realizado em uma escola estadual no Paraná com 55 alunos do $7^{\circ}$ ao $9^{\circ}$ ano no contra-turno.

Destaca-se que as atividades deste projeto foram pensadas buscando contribuir com os Objetivos de Desenvolvimento Sustentável - ODS por alinharem-se a alguns destes [3].

Os resultados apresentados apontam que os alunos tiveram um aproveitamento considerável, nos dois primeiros módulos que foram aplicados. Além disso, uma grande parcela dos alunos consideraram as atividades desenvolvidas no curso prazerosas.

O presente trabalho é descrito na seguinte sequencia: logo após essa introdução é apresentado o referencial teóricometodológico necessário para entender o ambito do que foi realizado; na sequência é descrita a metodologia utilizada, os resultados e discussões obtidos e por fim são apresentadas considerações finais sobre o trabalho.

\section{REFERENCIAL TEÓRICO-METODOLÓGICO}

Segundo Gomes e Melo [4] o pensamento computacional permite realizar um encadeamento sequencial e coerente de instruções com o propósito de resolução de problemas. Essa habilidade é primordial quando se trata de elaboração de algoritmos pois um bom algoritmo precisa de uma boa lógica.

O pensamento computacional pode ser considerado como uma característica fundamental do ser humano e não apenas dos profissionais da computação, como a capacidade de ler, escrever, falar e fazer operações aritméticas [1]. Essa afirmação se dá pelo fato que mesmo se o indivíduo procurar outros ramos que não sejam a programação, terá competência para resolução de problemas úteis para o contexto em que estiver inserido [2].

Existe um movimento se popularizando de ensino de conceitos de computação sem utilizar qualquer tipo de meio eletrônico, software ou hardware, denominado de computação desplugada. Esses conceitos podem ser de sequência de instrução, laços de repetição, condições, busca e ordenação, entre outros.

Segundo Terçariol et al. [5], a falta de infraestrutura básica não deve ser considerada um empecilho para estimular a capacidade do pensamento computacional pois cada 
instituição deverá analisar o seu contexto e a partir dela adotar alguma metodologia de inclusão digital. Por conta disso a computação desplugada se apresenta como uma excelente solução para esse problema.

Esse tipo de metodologia tem o intuito de trabalhar a questão do lúdico pois conseguem manter os alunos interessados por mais tempo em atividades consideradas cansativas e enfadonhas [6] muito comum em atividades relacionadas a computação, principalmente nos conceitos básicos.

As atividades desplugadas possuem a capacidade de lidar com as problemáticas do cotidiano sob um contexto computacional e vice-versa, estimulando a capacidade do aluno de abstrair e buscar soluções. Elas não dependem de ferramentas eletrônicas, por isso torna-se possível ensinar computação em qualquer lugar, usando o mínimo de materiais, como por exemplo, um papel e uma caneta ou simplesmente giz.

O site Code.org ${ }^{1}$ é uma organização que tem como propósito expandir o acesso e a informação da ciência da computação nas escolas. Ele possui várias atividades com recursos lúdicos para o ensino de conceitos de computação utilizando blocos de instruções interativos.

Essas atividades são separadas em cursos, destinados a faixa etárias que vão desde crianças de 4 anos até adolescentes.

O site ainda elaborou um projeto denominado "Hora do Código" composto por atividades que duram no máximo uma hora, para que várias escolas possam trabalhar conceitos de computação sem precisar se aprofundar ou oferecer um curso mais longo. Esse projeto é um movimento global em que várias escolas tiram uma hora para realizar atividades sobre computação.

\section{METODOLOGIA}

O curso ofertado utilizou as atividades do code.org. Dentre as atividades sugeridas no site, foram realizadas as de programação com blocos de instruções interativos e algumas desplugadas.

As atividades propostas incluem oportunidades de interdisciplinaridade pois promovem discussões de geometria, noção de matrizes, interpretação de texto e um breve contato com a língua inglesa.

O projeto de extensão foi aplicado por um grupo de quatro docentes e 10 discentes, do curso de Ciência da Computação da Universidade Estadual do Oeste do Paraná do campus de Foz do Iguaçu (Unioeste). A equipe foi formada buscando contribuir com igualdade de gênero, com 2 professores e duas professas, e 5 monitores e 5 monitoras, desta forma contribui-se não somente com oportunidades iguais mas também dando o exemplo aos alunos da presença e importância da participação de todos. Além disso o projeto

\footnotetext{
${ }^{1}$ Disponível em: https://code.org/
}

contribui também para os ODS educação de qualidade e redução das desigualdades [7][8].

O grupo foi dividido em três equipes, cada uma com pelo menos um docente e um discente presente. $\mathrm{O}$ curso foi ofertado duas vezes na semana, durante 4 semanas e meia. Cada aula durou cerca de duas horas, ocorrendo sempre no contra-turno. Ele obteve uma carga horária total de 20 horas.

As aulas foram realizadas no laboratório de informática da própria escola utilizando computadores que possuíam acesso a internet. Em alguns casos os alunos se sentavam em dupla, pois o Code.org permite adicionar um colaborador, para que ambos possam ser considerados autores da resolução do problema.

No total o curso foi frequentado por 55 alunos do $7^{\circ}$ ao $9^{\circ}$ ano. Inicialmente foram realizadas atividades desplugadas explorando o conceito de algoritmos com o intuito de apresentá-lo de maneira concreta. Observou-se que para a maioria era o primeiro contato com o conceito.

As atividades foram realizadas utilizando uma matriz impressa, conforme mostra a Fig. 1, contento um ponto de partida. Foram estabelecidos com os alunos o objetivo (colorir os quadrados indicados na matriz entregue) e as instruções permitidas. Desse modo eles construíram um algoritmo, ou seja, indicaram uma sequência de instruções necessárias para atender ao objetivo definido. Outra atividade desplugada realizada com os alunos foi pedir para que, a partir de uma matriz em branco e uma sequência de instruções, executassem o algoritmo, produzindo uma matriz com algumas células coloridas.

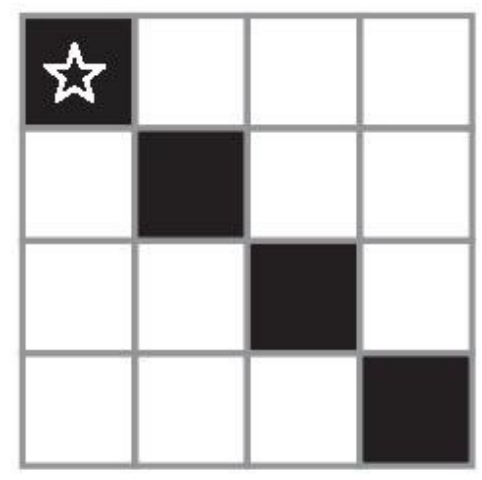

Figure 1. Matriz de referência para elaboração de algoritmo.

Uma outra dinâmica explorada fez uso da lousa. O intuito era aumentar a interação entre os envolvidos no curso (alunos/docente/discentes). Foram propostos problemas para serem resolvidos em conjunto. Os alunos indicavam as instruções que foram executadas na lousa de modo que todos acompanhassem e pudesse interagir, como pode ser visto na Fig. 2

Depois dessa introdução do conceito de algoritmo, os alunos exploraram de maneira individualizada o "Curso 2" da plataforma Code. Embora esse curso seja recomendado 


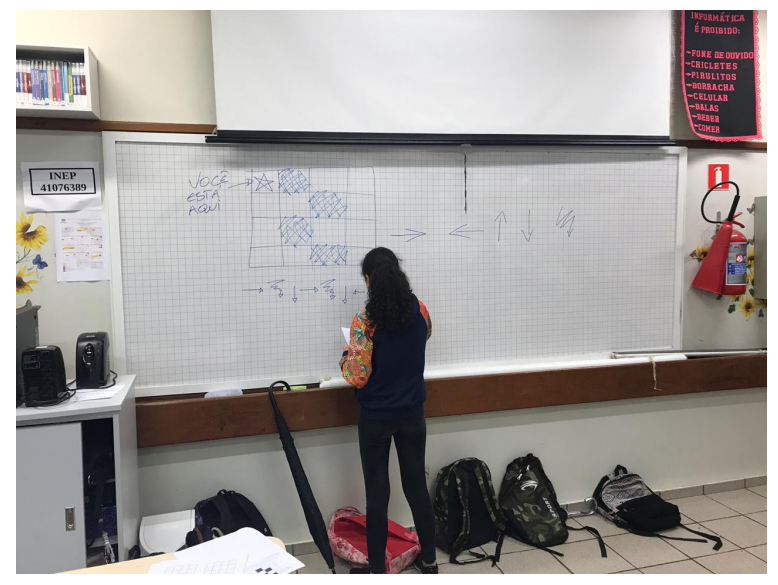

Figure 2. Resolução de atividades feitos na lousa.

para alunos de $2^{\circ}$ ao $5^{\circ}$ ano, ele é considerado como adequado para iniciantes, pois possui atividades com um nível moderado de complexidade, além disso, aborda conceitos iniciais de algoritmo. Essas atividades são compostas principalmente em deslocar um personagem por um tabuleiro utilizando blocos de comandos de avançar, virar à direita e virar à esquerda, sendo acrescentado mais blocos à medida que avança-se. Outros blocos importantes são os blocos de repetição e os de decisão, como visto na Fig. 3 .

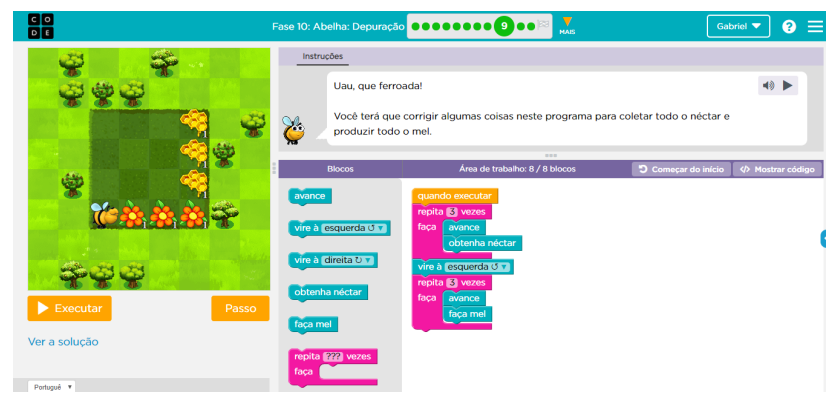

Figure 3. Atividade do Code.org sobre depuração.

Esse curso é dividido em 19 lições, sendo composta em média por 10 atividades que trabalham com conceitos de algoritmo, repetição ou laços, programação por revezamento, depuração, condições, números binários, laços, entre outros. As atividades são elucidadas em labirintos ou formas geométricas, nesse caso utiliza-se de conceitos matemáticos como ângulos, para desenvolver a atividade proposta.

Como a realização das atividades no code.org ocorriam de maneira individual, alguns alunos avançaram mais rapidamente. À medida que foram finalizando o curso 2, atribuíalhes a tarefa de monitoria no curso como forma de reconhecimento de seus esforços e como estímulo aos demais. Desse modo eles auxiliavam outros alunos aumentando a interação da turma.

Para aqueles que tinham finalizado o "Curso 2" e tinham desenvolvido a monitoria durante algumas horas, foi dado sequência com o "Curso 3".

O "Curso 3" possui o mesmo tipo de atividades que o "Curso 2", porém com um nível a mais de complexidade. Ele é um aprimoramento da lógica de condições de laços, exercitando lógicas mais abstratas, como laços aninhados.

Poucos alunos avançaram até o "Curso 4", no qual é introduzido o conceito de função que são caixa de blocos de comandos a parte que podem ser adicionados na sequência principal de comandos de acordo com a necessidade.

\section{RESULTADOS E DISCUSSÕES}

Buscando mensurar o impacto do curso no aprendizado, os alunos foram convidados a responder um questionário ${ }^{2}$ composto por duas partes: uma para identificar a frequência do uso da tecnologia no cotidiano dos alunos e outra para medir o grau de satisfação quanto a experiência vivenciada no curso. Este questionário foi aplicado no último dia do curso, tendo sido respondido por 25 participantes.

Relacionado ao acesso às redes sociais, jogos, fins escolares ou para mais alguma coisa, observou-se que $60 \%$ dos matriculados acessam diariamente redes sociais (Fig. 4). Além disso, quase a grande maioria utiliza os aparelhos e dispositivos disponíveis para jogos e afins diariamente. Observa-se também que o maior índice da categoria nunca, foi registrado no uso dos dispositivos para fins educativos. Foi observado que grande parte dos alunos participantes, utilizam os aparelhos e dispositivos no entretenimento como jogos, séries e filmes, para tirar fotos, bem como para acesso a aplicativos como o Youtube.

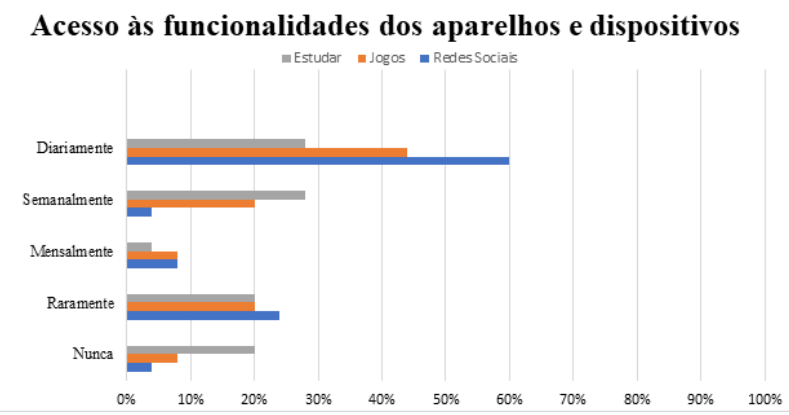

Figure 4. Frequência ao uso da tecnologia.

\section{A. Aprendizagem das lições}

Ao final do curso os alunos responderam um formulário relacionado a sua satisfação com relação as aulas ofertadas e conhecimentos adquiridos sobre programação de computadores e conhecimentos relacionados a outras disciplinas tais como inglês, matemática e português durante as lições desenvolvidas. A Fig. 5 mostra que mais de $80 \%$ dos participantes ficaram satisfeitos com o que foi aprendido no curso.

\footnotetext{
${ }^{2}$ Disponível em: http://tiny.cc/pensamentocomputacional
} 
Além disso, observa-se que não foi registrado respostas discordantes ou que revelassem insatisfação ao conteúdo das aulas. Portanto, nota-se que o período de curso foi prazeroso tanto pelas lições e aprendizagem desenvolvidas, como pela interação com os colegas, professores e monitores. Podemos observar uma opinião neutra e $11 \%$ dos dados sem respostas registradas. Assim conclui-se que as turmas reagiram positivamente ao que foi ofertado, revelando a eficiência dos métodos e atividades adotadas, bem como um bom nível de aproveitamento e interação entre os matriculados.

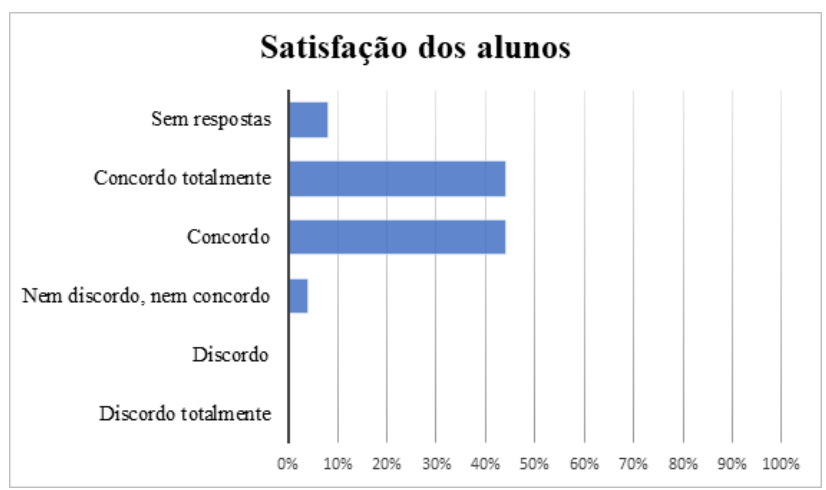

Figure 5. Satisfação dos participantes.

Em relação a aprendizagem das disciplinas de computação, inglês, português e matemática, a Fig. 6 mostra que os alunos concordaram que as atividades desenvolvidas no curso contribuíram com a aprendizagem.

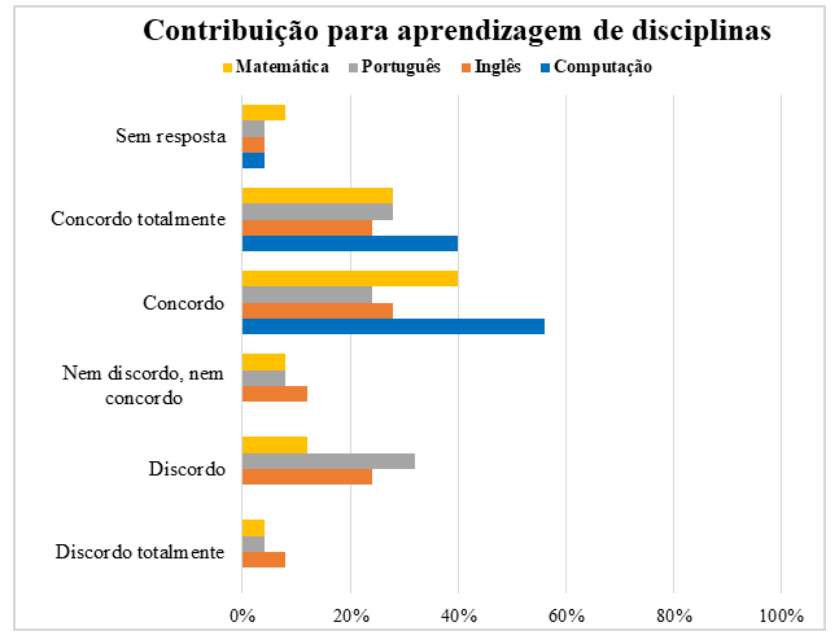

Figure 6. Aprendizagem de computação e matérias complementares.

Observa-se que nas matérias de língua portuguesa e inglês, as respostas encontram-se divididas em concordo, até mesmo totalmente e discordo, bem como $12 \%$ se mantiveram neutros em relação ao idioma inglês. Enquanto na disciplina de matemática, $40 \%$ dos alunos concordam com a aprendizagem efetiva em relação às contribuições, sendo a segunda maior porcentagem na categoria.
Vale ressaltar que quando o indivíduo toma consciência da importância em aprender o conteúdo, aumenta o seu interesse por aprender. Acredita-se que o curso além de contribuir com o aprendizado, tenha despertado a consciência dos alunos e isso irá refletir positivamente na sala de aula, visto que existe motivação e percepção da importância do conteúdo para sua vida.

De maneira geral, vemos respostas positivas e de concordância em sua maioria nas outras matérias, revelando assim um resultado satisfatório em vista das porcentagens apresentadas, mostrando a importância e necessidade de aliar a computação no ensino, produzindo assim resultados efetivos e satisfatórios, além de abrir e proporcionar um leque de opções e enriquecimento práticos no saber e no processo de construção de conhecimento.

De maneira geral, vemos respostas positivas e de concordância em sua maioria nas outras matérias, revelando assim um resultado satisfatório em vista das porcentagens apresentadas, mostrando a importância e necessidade de aliar a computação no ensino, produzindo assim resultados efetivos e satisfatórios, além de abrir e proporcionar um leque de opções e enriquecimento práticos no saber e no processo de construção de conhecimento.

\section{Frequência de uso de um aparelho ou dispositivo eletrônico}

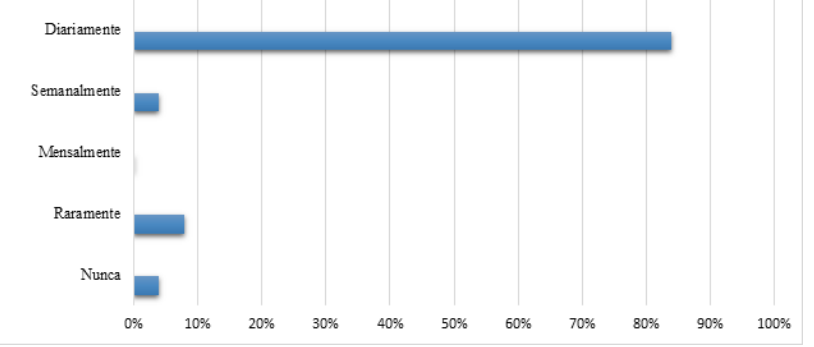

Figure 7. Frequência relativa ao uso de um aparelho ou dispositivo eletrônico.

Através da Fig. 7, verifica-se que $84 \%$ dos estudantes utilizam diariamente um computador, tablet ou celular. Já $8 \%$ dos matriculados utilizam raramente e $4 \%$ nunca utilizam esses aparelhos ou dispositivos, indicando uma parcela mínima, mas que revela fatores externos aliados a este dado, como a carência econômica e social, a falta de recursos e até mesmo de informações relacionadas ao uso, bem como a ausência de incentivo a utilização e suas possíveis funcionalidades.

\section{B. Aproveitamento dos Cursos}

O curso utilizou vários módulos do Code.org. Todos os alunos iniciaram pelo "Curso 2", a Fig. 8 apresenta o aproveitamento dos 55 alunos com relação ao "Curso 2". Pode-se perceber que $73 \%$ dos alunos finalizaram totalmente esse módulo, entretanto, $27 \%$ tiveram um aproveitamento 
parcial. Esses alunos representam os que desistiram durante o curso.

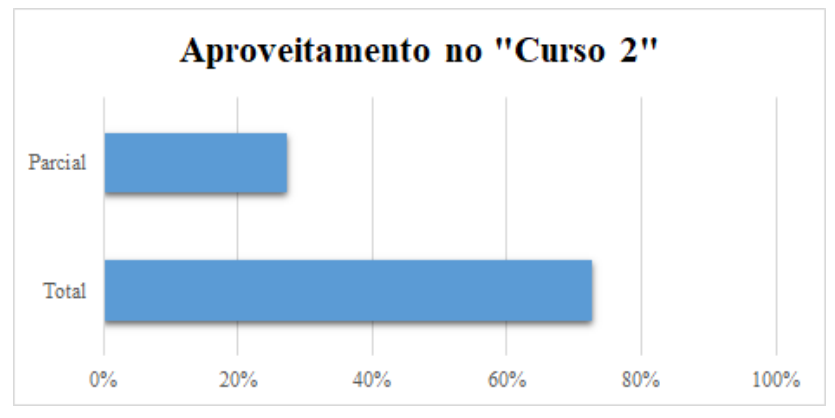

Figure 8. Aproveitamento do "Curso 2".

A Fig. 9 mostra o aproveitamento do "Curso 3", módulo seguinte para quem finalizou o "Curso 2". É possível observar que $20 \%$ dos 40 alunos que concluíram o "Curso 2" finalizaram completamente esse módulo. Os outros alunos obtiveram um aproveitamento parcial, porém não representam desistência, pois muitos não conseguiram concluir as atividades até a finalização do projeto.

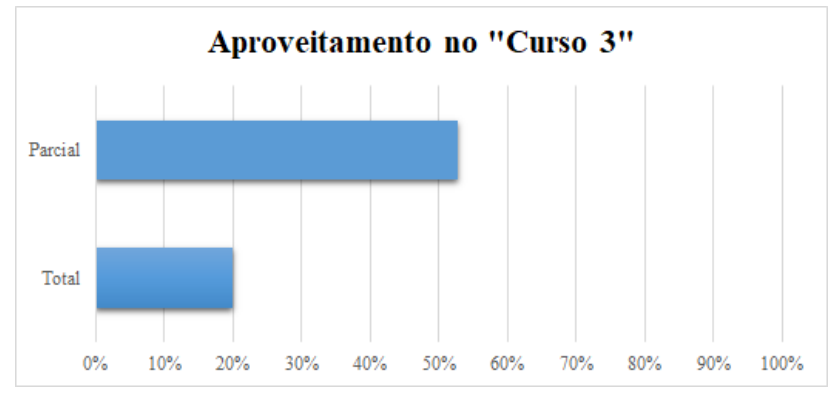

Figure 9. Aproveitamento do "Curso 3".

Nem todos os alunos que finalizaram o "Curso 3" deram continuidade ao "Curso 4", pois, como ocorreu no modulo anterior, muitos não terminaram a tempo. Na Fig. 10 pode-se perceber que apenas 5 alunos iniciaram o "Curso 4", o que representa 9\%. Porém, por terem iniciado no final do Projeto, não conseguiram ter o aproveitamento total do módulo.

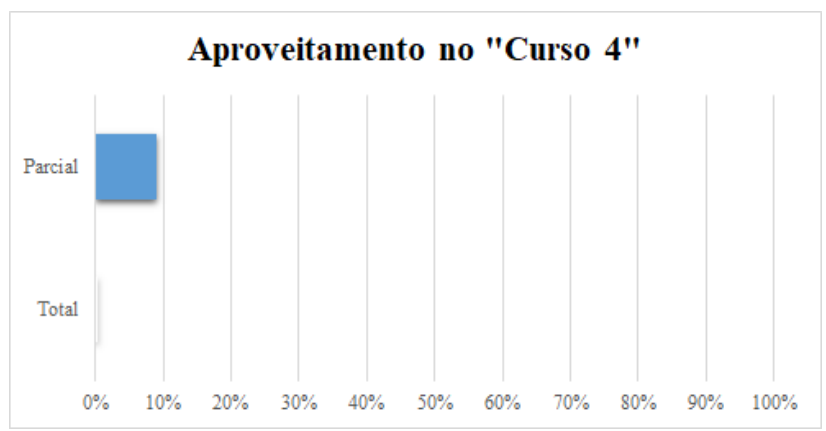

Figure 10. Aproveitamento do "Curso 4".

\section{Discussões}

Apesar das lições e desafios apresentados serem extracurriculares, os alunos se empenharam e participaram efetivamente no processo. E esse interesse, se deve em grande parte ao método das aulas de computação desplugada, que promovem a curiosidade, busca por soluções, interação através do trabalho em equipe, explorando o raciocínio lógico, através da matemática, termos em inglês, e contribuindo para a aprendizagem da língua portuguesa.

Além disso, foi introduzido a prática de programação no desenvolvimento de novas habilidades. Isso contribuiu para mudar a visão de como a computação é vista, e na forma de como explorá-la: de maneira divertida e criativa para construir conhecimento, expressar ideias imaginativas e concretizá-las através de um computador.

Assim, os resultados mostram as vantagens de se introduzir pensamento computacional a alunos do Ensino Fundamental, no sistema educacional, considerando principalmente que a rejeição ou dificuldades apresentadas foram mínimas, e os percentuais de satisfação em relação ao curso foram altamente positivos.

\section{CONSIDERAÇÕES FINAIS}

Neste projeto foi possível observar a aplicação de um curso de ensino de algoritmo e programação para alunos de $7^{\circ}$ ao $9^{\circ}$ ano de uma escola fundamental. As abordagens escolhidas para trabalhar o pensamento computacional foi a computação desplugada e atividades de programação visual, utilizando blocos de comandos.

Estimular o pensamento computacional durante o ensino fundamental permite que jovens tenham a capacidade de melhorar o modo de organizar as ideias de forma eficiente para abstração de problemas, sendo útil em resolução de problemas matemáticos e na interpretação de textos e na solução de problemas do cotidiano.

Além disso os alunos, em sua maioria, se sentiram motivados em relação as atividades realizadas no projeto e seus impactos nas disciplinas de matemática, português e inglês.

Como trabalho futuro, pretende-se reaplicar o curso em uma nova turma de alunos e a criar um curso voltado a robótica educacional para os alunos que participaram desse projeto; deseja-se também executar um estudo mais aprofundado, por meio de testes e questionários antes e depois da condução das atividades; É de interesse também identificar o impacto do curso no desempenho escolar.

\section{AGRADECIMENTOS}

Agradecemos ao Grupo de Pesquisa DETAE da Unioeste, aos funcionários e alunos do Colégio Estadual Flávio Warken de Foz do Iguaçu e aos discentes da Unioeste: Eliton M. Franco, Camila M. Rodriguez, Carina A. de Moraes, Carlos Pedroso, Jedson G. F. de Paula, Natã R. C. de Jesus, Gisele V. Cassuboski e Yasmin F. do Carmo, que se dispuseram para a tarefa de monitoria no curso. 


\section{REFERENCES}

[1] J. M. Wing, "Computational Thinking," COMMUNICATIONS OF THE ACM, vol. 49, no. 3, pp. 33-35, 2006.

[2] M. L. S. de Oliveira, A. A. de Souza, A. F. Barbosa, and E. F. S. Barreiros, "Ensino de lógica de programação no ensino fundamental utilizando o Scratch: um relato de experiênciaOliveira, M. L. S. de, Souza, A. A. de, Barbosa, A. F., \& Barreiros, E. F. S. (2014). Ensino de lógica de programação no ensino fundamental utilizando o Sc," Congresso da Sociedade Brasileira de Computação - CSBC, vol. 12, no. 2006, pp. 1-10, 2014. [Online]. Available: http://www.lbd.dcc.ufmg.br/colecoes/wei/2014/0022.pdf

[3] "Transforming our world: the 2030 Agenda for Sustainable Development $\therefore$ Sustainable Development Knowledge Platform." [Online]. Available: https://sustainabledevelopment.un.org/post2015/transformingo urworld

[4] T. C. S. Gomes and J. C. B. de Melo, "O Pensamento Computacional no Ensino Médio : Uma Abordagem Blended Learning," XXI Workshop sobre Educação em Computação WEI. Anais do XXXIII Congresso da Sociedade Brasileira de Computação - CSBC., no. May, pp. 651-660, 2013.

[5] A. A. d. L. Terçariol, M. d. S. Mandaji, R. K. da Silva, and G. L. Mazurkievicz, "O PENSAMENTO COMPUTACIONAL NA ESCOLA: PRINCÍPIOS NORTEADORES E AÇÕES EM REDE," 2018.

[6] R. V. Cordovil, J. C. R. de Souza, and V. B. d. N. Filho, "LÚDICO: ENTRE O CONCEITO E A REALIDADE EDUCATIVA," Fórum Internacional de Pedagogia - FIPED, p. 6, 2016.

[7] D. Griggs and E. Al., "Sustainable development goals for people and planet," Theory and Science, vol. 495, no. 7441, pp. 305-307, 2013. [Online]. Available: www.cbd.int/sp/

[8] R. W. Kates, T. M. Parris, and A. A. Leiserowitz, "What is sustainable development? Goals, indicators, values, and practice," Environment, vol. 47, no. 3, pp. 8-21, 2005. 